\title{
Revisiting learning in higher education-Framing notions redefined through an ecological perspective
}

\author{
Crina Damsa, Alfredo Jornet \\ University of Oslo, Norway \\ Article received 15 September / revised 8 January / accepted 22 February / available online 10 January
}

\begin{abstract}
This article employs an ecological perspective as a means of revisiting the notion of learning, with a particular focus on learning in higher education. Learning is reconceptualised as a process entailing mutually constitutive, epistemic, social and affective relations in which knowledge, identity and agency become collective achievements of whole ecosystems. This conceptualisation implies that learning involves a trans-contextual and multimodal process, in which both learners and their social and material environments change. This article examines the implications of an ecological perspective on framing notions central to learning and current educational research, namely (a) knowledge co-construction and epistemic agency, (b) the role of (material) knowledge resources in the learning process and (c) the trans-contextuality that characterises learning in today's knowledge society. The discussion concludes by identifying prospects that an ecological perspective offers to education and research on learning in higher education. The insights emerging from this reconceptualisation imply changes in the ways we can enhance and analytically account for the transformative potential of education. They also indicate the necessity for further advancing our understanding of learners' ways of assembling the epistemic spaces necessary to engage in meaningful learning, their agency in this process and their relationship with the (social and material) environment.
\end{abstract}

Keywords: higher education, ecological perspectives on learning, co-construction of knowledge, agency, materiality, trans-contextuality, transformative nature of learning 


\section{Introduction}

This article revisits the notion of learning, particularly in the context of higher education, by discussing key ideas derived from an ecological perspective. Such a perspective is timely, considering today's complex epistemological, social and institutional context, in which interdependent links between human subjectivities, collective human cultures and their environments are becoming more visible. Learning is no longer viewed as the mastering of a given subject; it involves being knowledgeable across a variety of contexts, with the ability to connect to remote knowledge resources, communities and (work) sites no longer bound to one particular physical context (Carvalho \& Goodyear, 2015; Säljö, 2010). An ecological perspective is of particular interest in higher education, in which changing societal contexts and knowledge dynamics are creating new, open-ended and often unexplored opportunities and challenges in helping learners create professional futures. We are particularly interested in the broadening connections emerging between learning settings in higher education and in other contexts, in which curricular crossovers between scholarly knowledge and professional practices or cross-boundary learning arrangements (such as internships) are frequent. More knowledge is needed about the kind of learning opportunities that emerge as students, educators, professionals and other actors enter into new social and material configurations that are essentially uncertain and open-ended (Markauskaite \& Goodyear, 2014; Richter et al., 2015)..

The aims of this article are to elaborate on the ecological premises that underlie existing sociocultural, situative and sociomaterial approaches and to discuss the implications for learning research and practice. Thus, in this article, we do not develop a distinctly new approach, but rather make visible and elaborate on essential premises that are common to these other frameworks but which often remain tacit or underdeveloped. Most importantly, an ecological perspective conceives of learning as an irreducible, mutually constitutive set of relationships between individuals and their social and material environments. Thoroughly following this conception leads to new insights about how learners and social contexts develop together, and it also challenges the remaining dualisms present in the literature. We begin this article by laying out the basic premises of an ecological perspective. Drawing on an empirical study of project-based, collaborative learning in higher education, we then revisit notions important in current educational research, namely knowledge co-construction and agency, knowledge resources and materials and trans-contextuality. In each case, we discuss how a consideration of the ecological premises allows us to reconceptualise these notions, highlighting aspects of learning that are not so visible when these premises are implicit or simply ignored.

\section{Learning from an ecological perspective}

Ecology - the study of the relationships of organisms among one another and to their environmentis a central subject in biology. It has also been important for some of the most influential theories on learning and education. These include Vygotsky's (2012) cultural-historical theory, Dewey and Bentley's 1949/1999 views of knowing as entailing transactional-i.e., mutually transforming-relations between organisms and the environment, Gibson's (1979) ecological psychology and Bateson's (1972) theory of learning and communication. Common to these otherwise disparate scholars are two interlocked postulates that contrast with the individualistic and constructivist theories still present in current research on learning in general and in higher education in particular: (a) learning is not a private, internal process, but involves transactions between people and their socio-material environment, in which both people and environments are transformed; and (b) learning involves not only intellectual dimensions, but also practical and affective ones. In learning, the entire person-in-setting is transformed.

We elaborate on this viewpoint by highlighting arguments that propound an expansion of the 
sociocultural theory, emphasising its underlying relational ontology and transformative stance. Accordingly, human subjectivity, intersubjective (i.e., social) exchange, and material practice and production are irreducible aspects of a three-fold dialectical system (Stetsenko, 2008). The individual actively relates to the environment and other individuals, and those relations then come to form part of how a person relates to herself and how she comes to know and develop (Vygotsky, 1987). However, at the same time, the individual engages in the production of new material conditions, and thus acts upon and changes the world so that 'The individual could no longer be understood without his/her cultural means; and the society could no longer be understood without the agency of individuals who use and produce artefacts (Engeström, 2001, p. 134).

From an ecological perspective, learning involves not only epistemology-how we come to know things - but also, and most fundamentally, ontology (Packer \& Goicoechea, 2000). That is, knowledge, knowing and knowledgeable action are not ontologically separated from human development, but are inherently related to it. Viewed from this perspective, learning is not a process whereby stable, unchanging things become known by unchanging individuals. Rather, learning comprises changes in the conditions of human life and activity, in which both individuals and environments change. Dewey (1938/1997) captured this mutually transforming relation in the principle of the continuity of experience, in which, through experience of the world - and precisely because experience involves material and bodily engagement - the world changes, thus changing the conditions under which new experiences are had. This is a change that involves not only the intellect but the whole person and how one relates to oneself and to others. Experience changes not only the way we intellectually know the world but also the way we affectively and perceptually relate to it (Roth \& Jornet, 2014). Although these ecological principles, which imply the primacy of the social ecosystem over the individual, might not be new to readers familiar with sociocultural and situative approaches, their implications are still under-developed in the context of educational research and practice (Roth, 2015).

\section{Redefining key framing concepts from an ecological perspective}

To better understand how focus on the ecological premises described here contributes to reconceptualising learning, we revisit three notions that are important in current educational research and particularly important for higher education: (a) knowledge co-construction and agency, (b) knowledge resources and (c) trans-contextuality. We draw from a case involving groups of computer engineering students enrolled in an undergraduate introductory course in web design and development. The course included bi-weekly lectures in web development (e.g., HTML5, Java programming languages), lab sessions and a four-week collaborative web design and development project as the main course assignment. The student groups in the course were to receive guidance from the teachers and had various knowledge resources at their disposal. The setting is particularly interesting because it illustrates ways in which higher education programmes are attempting to prepare students to enter professional domains and societal contexts. We focus on one specific group mainly because their active and sustained engagement in the collaborative project illustrates both opportunities and challenges associated with the learning processes. Our description of the case is based on video-recordings of actual group interactions and group interviews. 
The focus group consisted of four male students with a genuine interest in software development. The group chose to design and develop a website for an external customer. Their learning process was characterised both by opportunities and challenges, related to both the learning of new content (i.e., the programming language and its application) and to ways of thinking and working in the field of web development. On the one hand, the students organised themselves effectively and employed varied and unexpected resources, most of them beyond the formal course curriculum (textbook). They organised the project work by dividing tasks and then holding long face-to-face meetings, during which they discussed strategy, searched for resources, integrated individually programmed codes and fixed bugs. They worked iteratively on their software product by developing and refining (paper and digital) mock-ups, following the methods of experienced web developers, which they explored online or by talking to experts. The group used and engaged with some resources provided in the course and with external resources from the web development community (crowd-source online programming platforms). The feedback on the developing product and on project management was mainly provided by the customer. On the other hand, the students experienced difficulties in understanding the complexity of the task's requirements. This often led to crashing prototypes and put pressure on the group's interaction. The students indicated that they found the project very interesting, but that the requirements were not specific enough and discussion often went on in circles, without a productive loop. These emerging issues were solved through group discussions, trial and error and by using clues found online and in customer feedback. This unplanned feedback compensated for the relatively little guidance received by the group. Although the group's assessment of the assignment was positive, they received a lower grade than they expected. The students critiqued the complexity of the task, which combined technical and project management challenges, neither of which were made completely clear in the assignment guidelines. In addition, the students considered that identifying and addressing errors before grading could have been facilitated by more sustained guidance during the development process.

\subsection{Redefining knowledge co-construction and agency}

The notion of knowledge construction is widely used in educational research (e.g., Schellens \& Valcke, 2006), most often to denote individuals' formations of mental models and representations. In an attempt to overcome focus on the individual, higher education research has more recently used the notion of co-construction to denote processes that focus on collective participation in learning activities and on transforming the environment (Damşa, Ludvigsen, \& Andriessen, 2013; Richter et al., 2015;). The case above clearly offers an example of such a co-construction process. The students worked jointly to create a product, and in this context, learning was the result not of an individual but of a social process, joint efforts and the resources involved. However, the notion of co-construction is often associated with a focus on how participants 'negotiate' meanings about given practices and topics (e.g., Heo, Kim, \& Kim, 2010). Here, a triad formed by subject, object and meaning is maintained, in which each of the three elements remains selfcontained and therefore ontologically primary. Co-construction thus turns the focus away from individual minds and toward joint group cooperation. However, in doing so, it still retains the ontological primacy of subjects and objects over the social, transformative process. Latour (2013) eloquently depicts this limitation: 'Every use of the word construction ... opens up an enigma as to the author of the construction' (p. 158). In the case of the student group described above, every step in the development process opened up new paths of inquiry and development, but it also forced the group to face new problems and choices. By engaging with these problems and activities, they generated new ideas and conceptual artefacts (the programming code), which in turn represented new departure points in their endeavour (Damşa \& Nerland, 2016).

An ecological perspective gives primacy to the social, shifting the focus away from subjects and objects and pointing to a 'a better appreciation of the material flows and currents of sensory awareness within which both ideas and things reciprocally take shape' (Ingold, 2011, p. 10). In the described case, the students 
develop a product together. Yet, the product itself is in constant transformation, taking different forms (sketches, drawings and prototypes). The students themselves do not have a clear idea of what they are in the process of 'co-constructing', and much of what happens is not planned, but emerges. There is not just jointly knowing, but there is also being uncertain, a condition that nonetheless does not impede the students' engagement in professional practices for which they have not yet developed expertise. As has been thematised in recent research on transfer taking and the ecological perspective, this participation is possible not because the individual students carry with them already formed understandings; rather, it is because there is an emergent constitutive order that cannot be attributed to the individual mind, but to an unfolding field of action (Damşa et al., 2010; Jornet, Roth, \& Krange, 2016). Here, the learner's receptivity, affectivity and competence to engage in social relations with others is primary over their individual (intellectual) intentions.

In analysing so-called co-construction events, the focus cannot be on either the constructing agents or the constructed objects, because both are constantly changing. This has implications for the notion of agency, which has not received adequate attention in higher education research (Ashwin, 2008). Some studies have begun to reconceptualise learning-related agency in terms of shared epistemic agency (Damşa et al., 2010). These studies have considered the social-relational aspects of learning and how knowledgegenerating processes become more than an individual endeavour. Transformative conceptions of agency are also being examined (e.g., Kumpulainen, 2013; Engeström, Sannino, \& Virkukken, 2014). Attention to the ecological premises creates the need to consider how collaborations involve affective and perceptual changes, in which learners are not only intellectual agents (how could they otherwise engage in practices for which they do not yet have the required knowledge?) but also subject to the performative and affective relations in which they engage (Roth \& Jornet, 2014). In the case presented here, the students not only (co)construct but draw from and appropriate cultural resources that are not their own. An ecological approach should be able to account for the role of these resources in ways that do not reify individual (agent, subject)tool (object, world) dualism.

\subsection{Redefining knowledge resources and materials}

Traditionally, domain-related knowledge has been 'translated' into classroom curricula that emphasise conceptual knowledge and understanding, in which teaching materials are often seen as involving knowledge representations or tools (Säljö, 2010). With the growth of ubiquitous information and communication technologies (ICTs), the range of knowledge resources available for teaching and learning has dramatically expanded. This is visible in the case above, in which the students did not turn to the textbook, but most often relied on online professional programming and/or social platforms. Classical literature has it that learning involves a process of interpreting and decoding representations to solve an already given problem. Not possibly knowing the domain and its practices in advance (learning these is the goal of the course), the students' engagement with resources and materials was problem- and world-forming. Yet, how materials partake in the formation of students' worlds (i.e., perceptions, knowledge or identity), that is, in processes of ontogenesis, is rarely discussed in connection to learning and research in higher education.

An ecological perspective is in line with recent sociocultural conceptualisations that view materials as meaning or sense-making resources (Säljö, 2010). According to this view, materials come to form integral part of thinking and doing through processes of sign formation (Vygotsky, 1987). It is not, as often is implied, that materials and technology 'mediate' between learners and the world, which would maintain Cartesian dualism (Stetsenko, 2005). Rather, materials become entangled with people's lives and form new organs, which cannot be reduced to either learner (subject) or material (object, tool) (Vygotsky, 1989). Learners orient towards materials, which organise the participants' perceptions and actions. At the same time, these actions transform the very materials that shaped them in the first place. Accordingly, the 'things' of learning - that is, 'teachers, learning activities and spaces, knowledge representations such as texts, pedagogy, curriculum content, and so forth' (Fenwick et al., 2012, p. 2) — cannot be taken for granted, but 
are seen as 'themselves effects of heterogeneous relations' (p. 2). In the case described above, the learning materials are diverse, but they certainly come to form an ecology that both organises and depends upon the organisation of the students' joint work. By coming into contact with knowledge resources related to professional practice (through delivering to customers, searching for information in professional and crowdfunded fora and using already existing codes), the participants are not so much being mediated to access knowledge as they are developing habits, dispositions and forms of orienting towards the epistemic, digital and physical world of which they already form an integral part (Damşa \& Nerland, 2016).

\subsection{Trans-contextuality}

An ecological perspective is relevant for explaining learning as a social and continuous process occurring across contexts and occasions. Individualist approaches rely on notions of transfer of knowledge to explain how learners move knowledgeably across contexts (e.g., Reed, 2012). Boundary crossing has been formulated as an alternative notion to account for how moving across settings involves social and material (rather than only mental and abstract) processes (Akkerman \& Baker, 2011). Taking the perspective of the students in our case, however, no explicit boundaries were apparent between their university setting and the professional world, in which they were already participating in several ways (through meetings, online or in contact with customers). Indeed, the students' concerns emerged with respect to both the formulation of the task (an aspect of schooling practice with which they are familiar) and aspects of the professional programming practices that may be said to be beyond the university's boundary. An ecological perspective challenges the notion of boundary, demanding instead an account that adequately describes the lines of becoming (intellectual, social and relational) that learners and materials together constitute and undergo. By crossing contexts, learners assemble an epistemic space (Markauskaite \& Goodyear, 2014), in which individual and collective goals, needs and epistemological orientations develop, capitalising on teaching and guidance, resources and infrastructure.

There are practical and methodological challenges associated with learning trajectories traversing time and space through (digital) technology (Carvalho \& Goodyear, 2015; Erstad, 2013). Learners have more access to information from a multitude of sources; it is a 'polyphonic' (Säljö, 2010), multi-contextual world. Although it is generally considered beneficial for learning, capitalising on widely available and distributed knowledge, resources and tools is not a straightforward process (Orlikowski, 2007). In our exemplary case, challenges and tensions emerged in relation to various aspects of the learning situation: the affordances offered by the state-of-the-art knowledge, practices and technologies, the students' positioning in relation to the tasks and the domain, and the teaching and assessment practices within the institutional setting. However, from a perspective that takes the ecological premises laid out here seriously, these challenges and tensions cannot be the result of self-contained learners, which inter-act with self-contained resources and self-contained (i.e., contained within boundaries) practices. As higher education continues to develop outreach practices in which schooling goes into professional practice, and vice-versa, we no longer have a crossing of boundaries, but a new line of development within which different materials and subjectivities unfold.

\section{Concluding remarks: Ecology and learning in higher education}

This contribution elaborates on considerations of learning as a set of mutually constitutive relationships among individual, institutional and societal contexts. The empirical material illustrates how, as a group of students engaged in actual relations in and across knowledge domains (e.g., the school, the professional field of software programming), there is not just co-construction of knowledge but also reconfiguration of their affective and relational orientations. While learning software development and 
programming, the students generated knowledge and re-enacted practices and objects (see Stetsenko, 2005) that fed into and transformed their knowledge landscape and their personal horizons.

In line with the transformational ontology posited by the ecological perspective, a reconsideration of the role of higher education involves preparing people to not only learn and adapt to existing knowledge, practices and environments but also to actively transform them (Stetsenko, 2008). Such a perspective has the potential to guide learners, education and society towards a notion of learning that accounts for the fluid elements of the epistemic, social and material-digital environments we are surrounded by and partake in (Ingold, 2011; Säljö, 2010). Within this augmented learning context, the role of formal educational settings, such as higher education, entails more than simply organising learning and helping learners go through authoritative obligatory passage points (Callon, 1984). It needs to offer resources to allow students become critical and productive participants, helping them manage their own learning and development trajectories. Acknowledging that learning is an achievement of whole (eco-) systems, and not primarily of individuals alone, educational settings should orient not towards individuals but towards transformational potentials. If learning is not about acquiring knowledge but about changing the world, then providing tools and opportunities for that change should become primary. An ecological perspective thus addresses the need to view learning not from a normative perspective-i.e., in terms of the competences we want learners to achieve - but in terms of the life world of the learner, for whom the structures in the world (and the boundaries thereof) are not the same as that of the educator or researcher. The insights emerging from this reconceptualisation indicate the necessity for a more sophisticated and versatile account of the transformative potential of learning and for advancing our understanding of learners' authoritative positioning and agency in learning (Kumpulainen, 2013), their relationship with the (epistemic, social and material) environment and the way they assemble the epistemic space necessary to engage in meaningful and transformative learning.

\section{Keypoints}

This article

* provides an ecological perspective for revisiting premises and notions fundamental to learning and development, in relation to higher education contexts,

* expands on current sociocultural and sociomaterial theories by proposing learning as a transformative process whereby both the learner and the environment change, and which entails development that is not only intellectual but also social and affective,

- builds on empirical material from a study of a higher education course aimed at bridging educational and professional contexts and

* challenges higher education to reconsider the premises for defining learning and to provide the appropriate framework for transformative learning to take place and for remaining dualistic viewpoints to be overcome.

\section{References}

Akkerman, S. F., \& Bakker, A. (2011). Boundary crossing and boundary objects. Review of Educational Research, 81(2), 132-169.

Ashwin, P. (2008). Accounting for structure and agency in 'close-up' research on teaching, learning and assessment in higher education. International Journal of Educational Research, 47, 151-158.

Bateson, G. (1972). Steps to an ecology of mind: Collected essays in anthropology, psychiatry, evolution, and epistemology. Chicago, IL: University of Chicago Press. 
Callon, M. (1984). Some elements of a sociology of translation: Domestication of the callps and the fishermen of St Brieuc Bay. The Sociological Review, 32, 196-233.

Carvalho, L., \& Goodyear, P. (2014). The architecture of productive learning networks. New York, NY: Routledge.

Damşa, C. I., Kirschner, P. A., Andriessen, J. E. B., Erkens, G., \& Sins, P. H. M. (2010). Shared epistemic agency - An empirical study of an emergent construct. Journal of the Learning Sciences, 19(2), 143-186. doi:10.1080/10508401003708381

Damşa, C., Ludvigsen, S., \& Andriessen, J. (2013). Knowledge co-construction - Epistemic consensus or relational assent? In M. Baker, J. Andriessen, \& S. Jaarvela (Eds.), Affective learning together: Social and emotional dimensions of collaborative learning (pp. 97-119). London, England: Routledge Academic Publishers \& Taylor and Francis Group.

Damşa, C.I., \& Nerland, M. (2016). Student learning through participation in inquiry activities: Two cases from teaching and computer engineering education. Vocations and Learning, doi:10.1007/s12186-0169152-9

Dewey, J. (1997). Education and Experience. New York, NY: Touchstone. (Original work published 1938)

Dewey, J., \& Bentley, A. F. (1999). Knowing and the known. In R. Handy \& E. E. Hardwood (Eds.), Useful procedures of inquiry (pp. 97-209). Great Barrington, MA: Behavioral Research Council. (Original work published 1949)

Engeström, Y. (2010). Expansive learning at work: toward an activity theoretical reconceptualization. Journal of Education and Work, 14(1), 133-156.

Engeström, Y., Sannino, A., \& Virkkunen, J. (2014). On the methodological demands of formative interventions. Mind, Culture and Activity, 21(2), 118-128. doi:10.1080/10749039.2014.891868

Erstad, O. (2013). Digital learning lives: Trajectories, literacies, and schooling. New York, Bern, Berlin, Bruxelles, Frankfurt am Main, Oxford, Wien, Peter Lang Publishing Group.

Fenwick, T., Edwards, R., \& Sawchuk, P. R. (2012). Emerging approaches to educational research: Tracing the socio-material. London: Routledge.

Gibson, J. J. (1979). The ecological approach to visual perception. Boston, MA: Houghton Mifflin.

Heo, H., Lim, K. Y., \& Kim, Y. (2010). Exploratory study on the patterns of online interaction and knowledge co-construction in project-based learning. Computers \& Education, 55, 1383-1392.

Ingold, T. (2011). Redrawing anthropology: Materials, movements, lines. Aldershot, England: Ashgate.

Ingold, T. (2015). The life of lines. London, England: Routledge.

Jornet, A., Roth, W.-M., \& Krange, I. (2016). A transactional approach to transfer episodes. Journal of the Learning Sciences. doi:10.1080/10508406.2016.1147449

Jornet, A., \& Steier, R. (2015). The matter of space: Bodily performances and the emergence of boundary objects during multidisciplinary design meetings. Mind, Culture, and Activity, 22, 129-151.

Kumpulainen, K. (2013). The legacy of productive disciplinary engagement. International Journal of Educational Research, 64, 215-220. doi:http://dx.doi.org/10.1016/j.ijer.2013.07.006

Latour, B. (2013). An inquiry into modes of existence: An anthropology of the moderns. Cambridge, MA: Harvard University Press.

Markauskaite, L., \& Goodyear, P. (2014). Professional work and knowledge. In S. Billett, C. Harteis, \& H. Gruber (Eds.), International handbook of research in professional and practice-based learning (pp. 79106). Dordrecht, Netherlands: Springer.

Orlikowski, W. (2007). Sociomaterial practices: exploring technology at work. Organization Studies, 28, 1435-1448. doi:10.1177/0170840607081138

Packer, J. M., \& Goicoechea, J. (2000). Sociocultural and constructivist theories of learning: Ontology, not just epistemology. Educational Psychologist, 35(4), 227-241. doi:10.1207/S15326985EP3504_02

Reed, S. K. (2012). Learning by mapping across situations. Journal of the Learning Sciences, 21, 353-398.

Richter, C., Allert, H., Albrecht, J., \& Ruhl, E. (2015). Grappling with the not-yet-known. In O. Lindwall, P. Häkkinen, T. Koschman, P. Tchounikine, \& S. Ludvigsen (Eds.), Exploring the material conditions of learning: The computer supported collaborative learning (CSCL) Conference 2015, Volume 1 (pp. 284-291). Gothenburg, Sweden: The International Society of the Learning Sciences. 
Roth, W.-M. (2015). The primacy of the social and sociogenesis. Integrative Psychological and Behavioral Science. doi:10.1007/s12124-015-9331-5

Roth, W.-M., \& Jornet, A. (2014). Toward a theory of experience. Science Education, 98, 106-126.

Schellens, T., \& Valcke, M. (2006). Fostering knowledge construction in university students through asynchronous discussion groups. Computers \& Education, 46, 349-370.

Stetsenko, A. (2005). Activity as object-related: Resolving the dichotomy of individual and collective planes of activity. Mind, Culture, and Social Interaction, 12(1), 70-88. doi:10.1207/s15327884mca1201_6

Stetsenko, A. (2008). From relational ontology to transformative activist stance on development and learning: Expanding Vygotsky's (CHAT) project. Cultural Studies of Science Education, 3, 471-491.

Säljö, R. (2010). Digital tools and challenges to institutional traditions of learning: Technologies, social memory and the performative nature of learning. Journal of Computer Assisted Learning, 26, 53-64. doi:10.1111/j.1365-2729.2009.00341.x

Vygotsky, L. S. (1987). The collected works of L. S. Vygotsky: Vol. 1. Problems of general psychology. New York, NY: Plenum.

Vygotsky, L. S. (1989). Concrete human psychology. Soviet Psychology, 27, 53-77.

Vygotsky, L. S. (2012). Thought and language (Rev. ed.). Cambridge, MA: MIT Press. (Original work published 1986) 